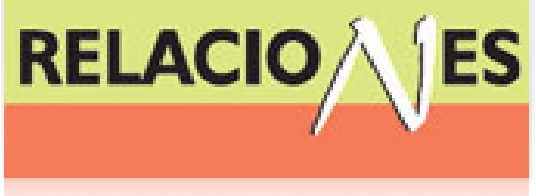

Relaciones. Estudios de historia y sociedad ISSN: 0185-3929

relacion@colmich.edu.mx

El Colegio de Michoacán, A.C

México

Naranjo Tamayo, Omayda

Pensativa de Jesús Goytortúa Santos: Imagen y representación de la mujer mexicana en la novela de tema cristero

Relaciones. Estudios de historia y sociedad, vol. XXXI, núm. 123, 2010, pp. 59-83

El Colegio de Michoacán, A.C

Zamora, México

Disponible en: http://www.redalyc.org/articulo.oa?id=13715893003

- Cómo citar el artículo

- Número completo

- Más información del artículo

- Página de la revista en redalyc.org

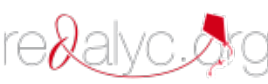

Sistema de Información Científica

Red de Revistas Científicas de América Latina, el Caribe, España y Portugal Proyecto académico sin fines de lucro, desarrollado bajo la iniciativa de acceso abierto 


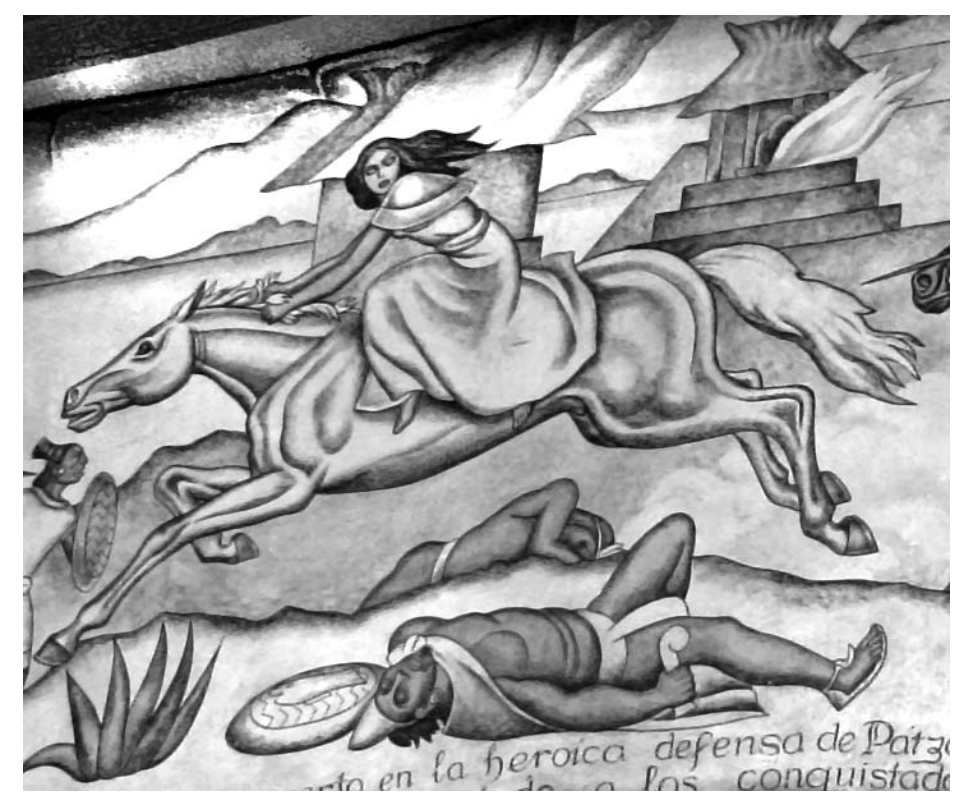

SECCIÓN Z EMÁtICA 


\title{
PENSATIVA DE JESÚS GOYTORTÚA SANTOS: IMAGEN Y REPRESENTACIÓN DE LA MUJER MEXICANA EN LA NOVELA DE TEMA CRISTERO
}

\author{
Omayda Naranjo Tamayo* \\ Universidad de Matanzas Camilo Cienfuegos, Cuba
}

Este ensayo explora, dentro del contexto de la Revolución mexicana, la representación de la mujer de finales de los años veinte del siglo pasado, a través de la novela Pensativa, de Jesús Goytortúa Santos. Es a su vez un estudio que destaca la presencia femenina en la historia a partir de uno de los géneros de la literatura, en una época matizada bajo la concepción familiar y social de que su rol debía circunscribirse únicamente al marco limitado del hogar. Se aborda su imagen a partir de su actuación durante la primera rebelión de los cristeros (1926-1929).

(Mujer, imagen, literatura, historia, rebelión cristera)

La novela de tema CRISTero en el conteXto de la Revolución MeXicana

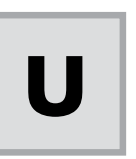

$\mathrm{n}$ acontecimiento como la Revolución mexicana de inicios del siglo XX, no pasó desapercibido por disímiles novelistas, poetas y literatos que desde diferentes ópticas interpretaron y relataron el suceso. Su impronta económica, social, política, ideológica y cultural, a partir de 1910 proporcionó a la nación, como fruto directo de ella, un sinnúmero de valiosas producciones literarias.

Hubo en la etapa algunos autores como Francisco Monterde (18941985) y Artemio del Valle-Arispe (1888-1961) por sólo citar dos exponentes, que se inclinaron en sus obras hacia la temática colonialista, abstrayéndose de la realidad histórica circundante que vivía el país. Con una evocación constante del pasado revelaron una suerte de reafirmación

\footnotetext{
*omayda.naranjo@umcc.cu
} 
nacionalista que, sin tener presente el compromiso con las transformaciones que se esperaban de la revolución en marcha, lograron ser eficaces voceros de lo autóctono, las tradiciones y las raíces naturales de México.

Por otra parte y de manera diferenciadora, las novelas que tuvieron como tema central a la revolución y sus complejidades sociales y políticas lo hicieron con un corte sorprendentemente realista y crítico. Sus máximos exponentes: Martín Luis Guzmán (1887-1976) y Mariano Azuela (1873-1952) trabajaron con sencillez y dinamismo el derrocamiento de la dictadura del presidente del país, general Porfirio Díaz Morí, pero sobre todo reflejaron en sus obras el desenvolvimiento de diferentes grupos sociales, y la actuación de los hombres y mujeres en medio de un nuevo orden de posibles cambios y transformaciones para la nación. Divulgaron y trasmitieron a la posteridad su propio accionar, revelando tanto la actuación de las principales figuras que se involucraron en la contienda, sus anécdotas variadas y sus hechos más importantes, como las demandas por el derecho a la tierra en lo relativo al problema agrario, el problema indígena y su violento acontecer.

María del Carmen Millán al caracterizar la novela de la revolución mexicana y develarla ciertamente como propensa al alegato personal ha afirmado que "las obras narrativas inspiradas por la revolución son parciales, fragmentarias y que presentan la fase histórica y política del movimiento con caracteres generalmente autobiográficos" ${ }^{\prime 1}$ Por otra parte como refiere Luis Mario Schneider "la revolución mexicana encontró mayores y más nutridos testimonios en la novelística que en cualquier otro género literario". ${ }^{2}$

Dentro del complejo itinerario de aquella revolución, entendido desde 1910 hasta 1940 cuando concluye el periodo presidencial del general Lázaro Cárdenas del Río (1934-1940), tuvo lugar un conflicto armado entre la Iglesia Católica y el Estado, conocido como la Rebelión de los Cristeros o la primera cristiada (1926-1929).

${ }^{1}$ Millán, "Panorama de la literatura mexicana", en Diccionario de escritores mexicanos, México, UNAM, 1967, p. XXIII.

${ }^{2}$ Schneider, La literatura mexicana, Buenos Aires, Centro Editor de América Latina, t. II, 1967, 25. 
Su escenario fue el centro-occidente de la república (mayoritariamente católico), con sus principales acciones en los estados de Jalisco, Zacatecas, Nayarit, Michoacán, Colima y Guanajuato. Al hablarse de la rebelión no se puede catalogar como un proceso sencillo u homogéneo, sino heterogéneo y muy complejo. Fueron en suma "tres años de lucha cruenta, sangrienta y desgarradora entre campesinos católicos cristeros y el gobierno federal mexicano [que] bastaron para convertirla en el sello nacional e internacional del gobierno posrevolucionario del general Plutarco Elías Calles (1924-1928)". ${ }^{3}$

Para entender el entramado de la rebelión de los cristeros necesariamente hay que tener en cuenta a los católicos y católicas del México de inicios de los años veinte y luego su oposición mayoritaria al gobierno del general Plutarco Elías Calles quien, instaurado en el poder desde el primero de diciembre de 1924 hasta 1928, siempre manifestó un acentuado sentimiento anticlerical. Por otra parte, la actitud del gobierno contra el amplio poder ideológico y económico que había alcanzado la institución católica mexicana desde antaño y las personas que lo profesaban nos conduce hacia los principales motivos, las actitudes que se manifestaron, los ataques, y los combates que libraron los dos grupos mexicanos, en pugna irreconciliable desde el mes de julio de 1926.

No se debe obviar la gran importancia y el papel determinante que desempeñó la religión católica desde el mismo nacimiento de la sociedad mexicana en los hombres y mujeres del país. Particularmente en el siglo xx llaman la atención las disposiciones que el presidente Calles quiso hacer cumplir estrictamente, específicamente los artículos 3, 5, 24, 27 y 130 que, con este carácter, habían sido incluidos en la Constitución de 1917 y que de una u otra manera influyeron decisivamente en el inicio de la rebelión de los cristeros.

A partir de 1926, respetando las disposiciones vigentes por parte del gobierno, en los disímiles estados de México se suspendía el culto público, se expulsaba a las monjas y los sacerdotes extranjeros del país, se tomaba posesión de propiedades de la Iglesia, se restringía el número de sacerdotes y se prohibía el hábito clerical en público. Igualmente se fo-

${ }^{3}$ Fuentes Mares, Biografía de una nación (De Cortés a López Portillo), México, Ediciones Océano, 1982, 257. 
mentó el crecimiento de la masonería y el protestantismo para contrarrestar la creciente influencia católica de la nación y se vigiló la instrucción en las escuelas parroquiales por el Estado. De manera similar se nacionalizaba al clero y se comenzaban a suprimir los colegios religiosos declarando públicamente la ilegalidad de las procesiones y los ritos fuera del templo. Todo ello trajo graves consecuencias para México y condujeron inevitablemente, con la conjunción de otros factores económicos, sociales y políticos, a tres años de lucha armada.

Fue un complejo y diverso acontecer donde hombres y mujeres lucharon de forma activa por la causa que defendían, fuese a favor o en contra de algunas de las disposiciones gubernamentales. Ello, unido a la agresividad de las batallas y acciones que se libraron y la diversidad geográfica donde tuvo su escenario cada una de ellas, fue revelado por un grupo de novelistas que a partir de entonces incursionaron en la inusitada temática.

Como temática predominante "del veintiocho al cuarenta, la Revolución es el tema monolítico [...] [y] escritores de raza y literatos necesitaron del tema central para sus obras literarias", ${ }^{4}$ sin embargo la mayor relevancia que manifestaron las novelas de tema cristero no consistió en su calidad como obras literarias, sino en el hecho de haber retomado el suceso armado como marco histórico de referencia, develando detalles y comportamientos que la historia tradicional de la época omitió.

El conflicto cristero generó una producción novelística y testimonial importante de personas que directamente vivieron el suceso. Diferentes novelistas oriundos de la nación como José Guadalupe de Anda, Elena Garro, Fernando Robles y Jesús Goytortúa Santos por sólo citar algunos, interpretaron el suceso con las particularidades y la filiación propias de cada uno, sin desdeñar en cada caso las disímiles polémicas y difíciles aristas que manifestó. Abordaron con ingeniosidad, conocimiento y valentía el candente conflicto de matiz político-económico-religioso que se había suscitado en el país. ${ }^{5}$ Todos, con la excepción del presbítero David

${ }^{4}$ Portal, Proceso narrativo de la revolución mexicana, Madrid, Espasa-Calpe,1980, 3.

${ }^{5}$ José Guadalupe de Anda escribió dos novelas relacionadas con el suceso, sus títulos fueron Los Cristeros y Los Bragados; Elena Garro recreó el tema de los cristeros en Los recuerdos del porvenir; Fernando Robles fue el autor de La virgen de los cristeros y Jesús Goytortúa Santos fue el autor de Pensativa. 
Ramírez (Jorge Gram, quien inició la literatura cristera con su novela Héctor en 1928) publicaron sus novelas luego de transcurridos varios años de la firma de los arreglos que dieron por finalizada la contienda armada, en el mes de junio de 1929.

En cada una de las obras de los novelistas de tema cristero la intención no fue únicamente "novelar" el hecho histórico que le dio lugar, sino la representación y acontecer de los diferentes grupos sociales involucrados en las diferentes zonas del país. Con sus novelas posibilitaron el estudio de la confrontación armada y su decisivo papel dentro de México, sin obviar en cada caso a las mujeres, fuesen combatientes en las acciones, enfermeras, espías, prostitutas, cocineras, militantes de las brigadas femeninas, maestras o sencillamente amas de casa que acompañaban a sus esposos en el intento frente al gobierno de reivindicar el derecho de profesar sin restricciones la fe católica.

La novela de tema cristero, como lo había hecho su antecesora la novela de la revolución mexicana, retomaba la historia para incorporarla a las expresiones de la literatura según las particularidades del género. Su diferencia con la anterior propuesta consistía en que abordó como temática fundamental las polémicas rivalidades Iglesia católica-Estado desde fines del siglo XIX e inicios del siglo XX, la relevante participación de la mujer mexicana, y los grupos campesinos como fuerza más importante de la rebelión.

La literatura cristera que indagó en las peculiaridades de sus actores, específicamente la novela, reflejó un conjunto variado de actitudes y manifestaciones de los hombres, mujeres y niños del pueblo mexicano. Enfatizó el criterio de que la novela como género literario es la mejor historia, al decir del crítico cubano Juan Marinello Vidaurrutia. Según su criterio "la historia, cualquiera sea su orientación es el testimonio de un tramo del tiempo y de la tierra [...] [y] el poder creador del novelista hace del hombre, del personaje, una suma inquieta de experiencias y sensaciones que vienen de su contorno y de un pasado que gravita sobre su destino". ${ }^{6}$

${ }^{6}$ Marinello Vidaurrutia, "Treinta años después. Notas sobre la novela latinoamericana", en Recopilación de textos sobre tres novelas ejemplares, La Habana, Serie Valoración Múltiple Casa de las Américas, 1975, 64. 
Con los recursos propios del género se develaba un periodo de la historia nacional que conmocionaba hondamente a la nación y que constituía por años y décadas una temática negada y por tanto no mencionada, menos aún estudiada con anterioridad con la seriedad que el tema merecía. Por otra parte sacaba a la luz un suceso inolvidable de parte de varias generaciones de mexicanos.

La novela de tema cristero se interesaba por mostrar las aristas diversas de un episodio sui generis acontecido en el país: el enfrentamiento armado entre dos poderes fuertes y antagónicos: La iglesia Católica y el Estado, y lo hizo con el desenfado natural de la literatura, la cual "expresó la diversidad del país que la historia oficial ocultó y en ese sentido nació descentralizada sin acatar o responder a las modas culturales del centro". ${ }^{7}$

\section{La Rebelión de los CRisteros en Pensativa: Conjunción de la} LITERATURA Y LA HISTORIA

El acercamiento y estudio de una de las novelas cristeras mexicanas: Pensativa de Jesús Goytortúa Santos, nos permite conocer desde las voces de un pequeño pueblo los hechos, actitudes y personajes que tuvieron un importante papel, tanto activo como pasivo dentro de la mencionada contienda. Se encuentra latente en sus páginas la recreación literaria de la historia luego de transcurridos quince años de su terminación.

La novela se publicó por primera vez en el año $1945,{ }^{8}$ por la Editorial Porrúa, cuando Jesús Goytortúa Santos tenía treinta y cinco años de edad. ${ }^{9}$ Un año antes había obtenido el Premio Miguel Lanz Duret, certamen aus-

\footnotetext{
${ }^{7}$ Martínez Assad, Regiones en la historia y en la literatura, en Conrado Hernández López, Historia y novela histórica, México, El Colegio de Michoacán, 2004, 62.

${ }^{8}$ Goytortúa Santos, Pensativa, México, Editorial Porrúa, 1945. Fue la edición utilizada en el presente trabajo.

${ }^{9}$ Nació en 1910 en San Martín Chalchequatla, estado de San Luis Potosí. En 1945 publicó su primera novela, Pensativa. Su segunda novela, Lluvia roja (1947) obtuvo también un galardón en concurso, el premio Ciudad de México en el año 1946. Publicó en ocasiones bajo los seudónimos de Claudio Vardel y Fidel. Tomado de: Ocampo de Gómez, Literatura mexicana contemporánea, Biobibliografía crítica, México, UNAM, 1965, 129.
} 
piciado desde 1941 por el diario El Universal..$^{10}$ De parte del jurado fue una decisión osada para su época. El hecho de haber seleccionado como ganadora una novela que recordaba dentro de la historia no publicada oficialmente un episodio muy dramático y todavía sensible en el imaginario colectivo, evidencia que pudieron existir razones muy diversas para ser elegida, una de ellas fue, sin duda, la presencia dentro de sus páginas, no exentas de una extrema violencia, de la calidad del texto.

No obstante, desde el punto de vista literario los críticos han manifestado diferencias de criterio respecto a su calidad. Reviste gran interés retomar las opiniones diversas que sobre la novela han trasmitido sus estudiosos en diferentes etapas. Max Aub la ha calificado como una "mediocre novela acerca de la revolución", ${ }^{11}$ mientras el chileno Fernando Alegría plantea que la crítica especializada la ubica como una novela de mérito literario que, aunque no participa directamente en el conflicto ideológico, alude al tema de los cristeros. ${ }^{12}$ De manera similar Ángel Arias Urrutia ha recomendado su lectura de manera obligatoria por considerarla excelente. ${ }^{13}$

Pensativa ha posibilitado el conocimiento y una profunda visión de los grupos cristeros donde los hombres dieron todo en una guerra por la fe y la virgen de Guadalupe -refiere John Brushwood-y donde sólo recuerdan su valentía y una realidad cruel en la que perdieron parte de su vida. Según su estudio "es importante también porque muestra que el autor está lo suficientemente apartado de los acontecimientos como para recrear la circunstancias, en vez de observarlos simplemente" ${ }^{14}$

La novela enfatiza en la relación fraterna de los líderes rebeldes cristeros con la tropa y su posición incondicional a la causa que los anima

${ }^{10}$ Los premios de años anteriores habían correspondido a Ciudad, de José María Benítez en 1941; El hombre de barro, de Adriana García Roel en 1942 y El jagüey de las ruinas de Sara García Iglesias en 1943.

${ }^{11}$ Aub, Guía de narradores de la revolución mexicana, México, Fondo de cultura económica, 1969, 26.

${ }^{12}$ Alegría, Breve historia de la novela hispanoamericana, México, Ediciones de Andrea, $1945,145$.

${ }^{13}$ Arias Urrutia, Cruzados de novela: Las novelas de la guerra cristera, Ediciones Universidad de Navarra, disponible en www.etcetera.com.mx.

${ }^{14}$ Brushwood, México en su novela, México, Fondo de Cultura Económica, 1993, 389. 
ante la posibilidad de morir o vencer en la lucha contra el gobierno, pero de la misma manera hace recaer la atención hacia la política de hostilidad y venganza que llevó a cabo el gobierno contra la Iglesia mexicana y los católicos, a los que se les observa por parte del gobierno como fanáticos carentes de raciocinio. Por ello se ha considerado además que la guerra cristera que muestra Jesús Goytortúa se caracteriza por su irracionalidad, por su fe ciega y por la brutalidad que llevaron a cabo ambas partes. Para Ruiz Abreu "es una novela de corte histórico obviamente y que forma parte de la novela de la revolución mexicana", ${ }^{15}$ aunque Carlos Martínez Assad nos indica que si algunos la ubican en la novela de la revolución mexicana están errados, porque se trata de la novela de la contrarrevolución. ${ }^{16}$

En correspondencia con lo anterior, el crítico cubano Manuel Pedro González ha planteado que es esencialmente una novela de tema amoroso combinado con el tema histórico que fue la guerra cristera. Revela que en ninguna otra novela vemos al desnudo la intolerancia y la ferocidad implacable de los soldados de Cristo, vistos desde la postguerra. Según su estudio no es una gran novela, pero sí es una novela bien hecha, con el conflicto visto retrospectivamente con todo el odio, la exaltación y el despecho del fracaso. ${ }^{17}$

Los hombres y mujeres que se reflejaron en la novela cuando la rebelión había finalizado se ven imposibilitados de actuar como lo hacían antes de 1926, porque un sentimiento de rencor hacia la actitud del gobierno los invade. Ellos han vivido cada instante de la difícil coyuntura creada por la rebelión y cada una de las acciones que se han librado en los campos. De la misma manera se han vuelto seres desconfiados de sus semejantes ante el estremecimiento que han sufrido por tres años de inseguridad, desconfianza y miedo. No sólo es odio de ambas partes lo que se deriva de cada palabra o diálogo que el autor emplea, es resentimiento tanto de parte de los católicos hacia el gobierno, como de las autoridades civiles del pueblo que representan al gobierno hacia los que

\footnotetext{
${ }^{15}$ Ruiz Abreu, La cristera una literatura negada (1928-1992), México, Universidad Autónoma Metropolitana-Xochimilco, 2003, 168-170.

${ }^{16}$ Martínez Assad, ob. cit., p. 59.

${ }^{17}$ González, Trayectoria de la novela en México, México, Ediciones Botas, 1951, 310-311.
} 
dieron y aún siguen insistiendo en ofrecer la vida por Cristo rey y la religión católica.

Al mencionar la importancia de Pensativa dentro del grupo de producciones que recrean el hecho, el mexicano José Luis Martínez hace referencia al

interés que muchos escritores -tanto conocidos como desconocidos- muestran por las seducciones y complejidades del género [donde] cada una representa un esfuerzo apreciable por conquistar la plenitud del difícil arte novelístico, por explorar nuevos caminos y por expresar, desde diferentes perspectivas, la realidad de México o la imaginación y la aventura de sus autores $[\ldots]^{18}$

Por la caracterización que realizó Antonio Avitia Hernández del conflicto a través de sus personajes, clasificó a Pensativa como novela neutral. Considera que en las novelas a favor de la cristiada:

Los personajes positivos son los hacendados, los cristeros y los sacerdotes al tiempo que los negativos son los agraristas, los maestros rurales y el gobierno. En el segundo tipo de novelas los "malos " son los hacendados, los cristeros y los sacerdotes. En el caso de las novelas neutrales los códigos se matizan y aparecen personajes poco usuales como el cacique y los burócratas corruptos. ${ }^{19}$

Aún cuando en Pensativa no aparecen como personajes ni los caciques ni los burócratas corruptos, puede considerarse perfectamente como una novela que intenta ofrecer los caracteres de cada una de las facciones en lucha sin un comprometimiento, menos aún filiación hacia una u otra causa. Su interés a diferencia de Jorge Gram en Héctor o Los cristeros del Volcán de Colima, de Spectator, no radica en plantear una abierta oposición a la revolución mexicana, sino en mostrar al lector una pro-

${ }^{18}$ Martínez, Literatura mexicana S. Xx (1910-1949), México, Antigua Librería Robredo, $1949,242$.

${ }^{19}$ Avitia Hernández, Las cristiadas noveladas, México, Proyecto de investigación de la Universidad Autónoma Metropolitana, 2003, 4-5. 
blemática donde las dos partes en pugna se enfrentaron durante tres años con la misma ferocidad, rencor y violencia.

Por otra parte, el estudioso César Aira no hizo mención en su trabajo a la denominación de novela anticristera, pero ha planteado que Goytortúa es de los que, a diferencia de autores como Fernando Robles o Jorge Gram, se colocan en una posición opuesta a la óptica católica para realizar la "novela de la guerra cristera" ${ }^{20}$

La reconstrucción histórica de un tema en extremo complejo naturalmente generó dicotomía de parte de los críticos que indagaban en su calidad teniendo en cuenta el manejo del lenguaje, la estructura, la descripción y el tratamiento del tema y de los personajes. Según el criterio de Ruiz Abreu las ideas comunes que expresaron las diferentes novelas cristeras son simples:

la del enfrentamiento entre un pueblo católico, azuzado por clérigos, católicos recalcitrantes, hacendados defensores del "anciénne régime", y mujeres beatas, y el Estado laico, necesitado de reafirmar su maquillaje revolucionario persiguiendo a la iglesia Católica ya que entorpecía seriamente sus planes de cambio social, político y su objetivo final de transformar la mentalidad de la gente. ${ }^{21}$

En la novela escrita por Goytortúa la creatividad imaginativa y la preferencia del autor por mostrar una visión particular de la rebelión de los cristeros nos conduce a la historia que cuenta la novela. En síntesis su trama gira alrededor de la situación de un pequeño pueblo y sus habitantes cuando el conflicto ha terminado. De una manera u otra se conoce por el narrador que todos en el pueblo se han visto relacionados con el suceso. Todos ellos, con excepción del protagonista que llega de la ciudad de México, han tenido una incidencia determinada en las disímiles acciones armadas, despiadadas y crueles que se han vivido desde 1926-1929. Los diálogos de Gabriela Infante, cuyo sobrenombre es Pensativa pone de manifiesto la participación de las mujeres y el papel dirigente y activo de las féminas en la contienda. Sólo al final de la novela la

\footnotetext{
${ }^{20}$ Aira, Diccionario de autores latinoamericanos, Buenos Aires, Emecé Editores, 2001, 33.

${ }^{21}$ Ruiz Abreu, ob. cit., p. 91.
} 
misteriosa y melancólica joven devela su verdadera identidad, conmocionando profundamente al joven Roberto que le ha pedido matrimonio sin conocer su pasado.

La narración de la novela inicia cuando el joven Roberto llega al pueblo de Santa Clara de las Rocas a visitar a su tía Enedina. Al llegar al pueblo y recorrer sus calles encuentra, luego de terminada la rebelión en 1929, "las calles invadidas por la hierba, sumergidas en un mortal silencio [donde] la guerra civil había herido con crueldad a [su] pueblo natal".$^{22} \mathrm{Al}$ indagar el protagonista en las causas del estallido de la rebelión de los cristeros, el secretario del Ayuntamiento del pueblo recuerda el temor que sintió ante las tropas cristeras conducidas por uno de los principales jefes de Jalisco, Carlos Infante, "tropas en extremo agresivas", que de encontrarlo sin duda no lo hubieran pensado para matarlo al instante. A través de las palabras del secretario se patentiza por el autor, tanto las diferencias irreconciliables entre cristeros y federales, como la actitud que manifestaron en la lucha armada que se libraba, de ahí que le respondiera al recién llegado:

Mire usted: Aquí los de ambos bandos, hablando con verdad, merecíamos lo que nos pasaba. Tan fanáticos y tan salvajes éramos los pintos como los colorados. El Presidente Municipal le había entregado las monjas de la Caballería, y [...] bueno, pues había hecho muchas cosas más. Los regidores también tenían sus pecaditos. Todos éramos deudores y acreedores y yo por eso digo: maldita sea la guerra civil, que rompe todas las leyes y que hace al hermano verdugo del hermano. ${ }^{23}$

Ante el conocimiento de una etapa difícil vivida en su país el protagonista considera entonces que creyó "ver brotar de la tierra un vapor enrojecido. Las guerras más dolorosas han bañado en sangre la tierra mexicana. Y las peores han sido las civiles; las más salvajes, las que han dado a cada árbol por fruto un ahorcado, han sido las luchas fratricidas" ${ }^{24}$ Su extrañeza a la tranquilidad que vivió en ese pueblo durante su

\footnotetext{
${ }^{22}$ Goytortúa Santos, Pensativa, p. 12.

${ }^{23}$ Goytortúa Santos, Pensativa, p. 79.

${ }^{24}$ Goytortúa Santos, Pensativa, p. 150.
} 
niñez contrasta con la ruina y la desolación que se respira por todos los sitios y rincones del pueblo cuando la rebelión finalizó. Luego, al conocer los detalles de las acciones confiesa su total desagrado por los que se dicen cristeros y califica de salvajes a quienes habían luchado en la guerra religiosa contra el gobierno por defender su fe. Su sorpresa aumenta sobremanera cuando se percata de que ambos bandos en pugna se habían visto involucrados en una guerra donde se cometieron atrocidades sin nombre y los mexicanos se habían convertido en bestias feroces, en hombres fanáticos, sedientos de sangre y soberbios que sólo soñaban con el exterminio del enemigo. Una indicación precisa, sugerida por el médico del pueblo, debe cumplir durante su breve estancia en Santa Clara de las Rocas: no debe hablar de los cristeros, porque la

zona produjo los cristeros a millares y aún hoy el pueblo está profundamente dividido. No sé cómo puede haber tanta gente que desee jamás la guerra civil. Nada hay más atroz que una lucha como la que tuvimos aquí, en la que la muerte se escondía tras de cada roca, en la que las familias luchaban entre sí. Creo que jamás se han cometido crímenes tan espantosos como los habidos en esa lucha $[\ldots]^{25}$

La primera rebelión de los cristeros había concluido en el pueblo cuando se relata por Goytortúa, pero había quedado en los hombres y mujeres del campo un sentimiento de tristeza y melancolía al recordarla. Los protagonistas, actores o simples espectadores de la contienda no habían podido olvidar el dolor que sintieron ante la pérdida de sus seres queridos que el suceso dejó a su paso.

El novelista insiste en mostrarnos lo que ha significado el mes de junio del año 1929 para los cristeros, pacto o arreglo que no ha tenido los resultados que esperaban. Desde el punto de vista histórico a mediados de 1929 al menos a corto plazo, los católicos cristeros no podían vencer tan fácilmente al gobierno como lo habían sugerido en 1926; y por otra parte, el gobierno mexicano sintiéndose en bancarrota desde el punto de vista económico, pero también en prestigio internacional, tenía extremada urgencia de terminar el conflicto cuanto antes, pero no fue objetivo

\footnotetext{
${ }^{25}$ Goytortúa Santos, Pensativa, p. 45.
} 
del novelista reflejarlo de esta manera. Al referirse a los polémicos acuerdos firmados entre el gobierno y los representantes de la Iglesia católica refería que los cristeros, estaban dispuestos a seguir luchando todo el tiempo que fuera necesario hasta obtener la derogación de las leyes que perseguían a la Iglesia católica.

El día 21 de junio de 1929 se dio a conocer en México la noticia de la solución entre la Iglesia católica y el Estado mexicano. A los "arreglos" no se le dio ningún carácter oficial y se retoma a través de uno de los diálogos de la novela. El gobierno no podía negociar con una institución a la que, desde 1917 en su artículo 130 constitucional, no se le reconocía personalidad jurídica alguna, de ahí la inconformidad que grandes grupos de combatientes cristeros manifiestan en la novela. Aunque el episcopado mexicano mantenía la solicitud de la modificación de las leyes anticlericales, no impuso ante el gobierno otras condiciones para el logro de la paz interna del país. Esta situación había determinado la ruptura entre la Liga de la Defensa de la Libertad Religiosa, la organización líder de los católicos y católicas, los grupos cristeros en armas y el clero. Cuando entre la jerarquía católica y el gobierno se llevó a cabo la firma de los arreglos que se conocieron como Modus Vivendi, la solución recogió entonces los siguientes términos:

1. Amnistía general para todos los levantados en armas que quisieran rendirse.

2. Que se devolvieran las casas curales y episcopales.

3. Que de alguna manera se garantizara la estabilidad de estas devoluciones. ${ }^{26}$

${ }^{26}$ Iraburu, La cristiada y los mártires de México. 2da parte, El curso de la guerra [material enviado por correo electrónico]. Otra mirada diferente la exponía el exporfirista mexicano Federico Gamboa. Refiriéndose a la firma de los arreglos entre la Iglesia y el Estado expresaba en su diario: "22 de junio de 1929: Se hacen públicos los términos del arreglo religioso: Primero: subsiste el registro obligatorio de sacerdotes, pero a indicación de los obispos. Segundo: Permitida la enseñanza religiosa, a horas que no sean escolares y dentro de los templos. Tercero: Reconócese al clero ¡el derecho de petición! [...] ¿Qué más podíamos apetecer? Añádase que por primera vez, del 1867 acá, el Estado trató con el clero de potencia a potencia.

23 de junio: [...] la Basílica y los templos, henchidos de fieles desde ayer, y el país entero, estremecido de júbilo [...]

29 de junio: Reanudación formal del culto con grandes ceremonias litúrgicas en la Profesa y en la Basílica de Guadalupe". 
En la novela, los habitantes del pueblo lamentan los resultados de 1929 cuando se ha dado a conocer lo pactado por los que no habían luchado físicamente en los campos mexicanos. Uno de ellos es Cornelio, uno de los combatientes católicos, quien está convencido de la justeza de la causa católica y de su decisión de haber luchado por los derechos religiosos de sus habitantes contra la hostilidad del gobierno. Cornelio "pertenece al número de los que se disgustaron con el clero cuando este firmó la paz con el gobierno" ${ }^{27}$ Decepcionado ante la solución definitiva del conflicto considera que "el clero es el primero en dar el ejemplo de sumisión a los herejes. Los sacerdotes se han olvidado de los libros sagrados y los obispos han firmado la paz con los amorreos. Íbamos de triunfo en triunfo cuando los obispos aceptaron la paz. Todo se perdió. Tanta sangre derramada en vano $[\ldots]^{\prime \prime} .^{28}$

Pesimismo y decepción ante la firma de los arreglos nos muestra Goytortúa. La rebelión soberbia y sangrienta que provocaron unos y otros y la no obtención de los resultados que se esperaban, incidía en los católicos hasta el punto de no aceptar su derrota frente al gobierno. Por otra parte, la Constitución vigente no fue modificada a partir de los arreglos, sino que sólo fue verbal el acuerdo de poner fin al conflicto de los cristeros. El novelista nos muestra a través de sus personajes la inconformidad con el gobierno, pero también la disposición de la jerarquía Católica de poner fin al conflicto, sin haber consultado su parecer con los cristeros que luchaban en los campos de batalla del país. A partir de 1929 , los templos fueron abiertos al culto para los católicos, pero con ello no se eliminaron totalmente las fricciones que se evidenciaron entre gobierno-estado, ni entre los mismos católicos mexicanos.

Jesús Goytortúa Santos escribió su novela Pensativa y la presentó en un concurso literario en 1945 cuando las huellas dejadas por los diferentes enfrentamientos y acciones armadas entre mexicanos aún estaban muy latentes en el sentimiento y la memoria colectiva del país. Desde el punto de vista oficial, por parte del gobierno hacer referencias o sencillamente relatar algún aspecto relacionado con la rebelión de los cristeros estaba vedado, sin embargo uno de los géneros de la literatura se con-

\footnotetext{
${ }^{27}$ Goytortúa Santos, Pensativa, p. 38.

${ }^{28}$ Goytortúa Santos, Pensativa, pp. 132- 134.
} 
vertía de esta manera en el vocero idóneo, a su vez capaz de realizar el rescate de la historia de uno de los sucesos más sangrientos y conmovedores de la nación.

Puede ubicarse dentro de las producciones literarias que forman parte del movimiento literario que se originó luego de finalizado el suceso, que además incluyó relatos, crónicas, testimonios, novelas, cuentos y corridos. Fungió en la práctica como una alternativa que difería de la concepción gubernamental de no mencionar siquiera los hechos, aristas, puntos de vista y resultados de la extrema complejidad que le caracterizó.

Pensativa resultó ser, una de las vías que posibilitó el recuento y el conocimiento del conflicto cristero, cuando el Estado mexicano quiso hacer olvidar a los oriundos de la nación una parte consustancial de su historia. Por otra parte, y de ahí su novedad, sobresalía como elemento significativo la representación del desempeño y rol femeninos en una época matizada por el confinamiento doméstico familiar. La mujer adquiría a través de uno de los géneros de la literatura una significativa mirada de su rol desde el punto de vista social.

\section{La mujer meXicana en Pensativa}

En las novelas de tema cristero se incorporó la representación de la mujer desde diferentes perspectivas, dígase la madre, las líderes, las que militaron en las brigadas femeninas, la maestra y las que protagonizaron otras acciones de menor envergadura. Todas centraron el interés de los novelistas dentro del complejo escenario del imaginario femenino.

Uno de los estudiosos de la temática, Frank León Gelskey Beier, coincidiendo con el criterio del novelista mexicano Juan Rulfo, ha planteado que en dicha novelística sobresale como nota distintiva la mujer, muchas veces como protagonista y otras como figura de gran relieve..$^{29} \mathrm{En}$ la novela Pensativa, de Jesús Goytortúa Santos, la actuación femenina dentro de la rebelión de los cristeros quedó consignada por su autor, funda-

${ }^{29}$ Tomado de Olivera de Bonfil, La literatura cristera, México, Instituto Nacional de Antropología e Historia, 1970, 105. 
mentalmente a través de la representación de una joven que devenía por su liderazgo en símbolo de la lucha entre cristeros y federales. El novelista, participante directo de la rebelión de los cristeros, se sintió sensibilizado e impresionado por la dinámica del hecho histórico y dentro del mismo por el rol femenino, de ahí la importancia de su obra en el aporte a la historia de la realidad social propias de la época que le tocó vivir.

La mujer adquirió como ser social, como sujeto histórico un papel de primer orden dentro de la amplia movilización que protagonizó el pueblo mexicano en el periodo 1926-1929, y ello fue reflejado por Goytortúa. En uno de los diálogos iniciales, Gabriela Infante conocida con el sobrenombre de Pensativa refiere que "en la guerra religiosa las mujeres participamos tanto como los hombres" ${ }^{30}$ A través de la joven protagonista se conoce que las mujeres campesinas del medio rural y las de clase media lucharon activamente. No fueron soslayadas ni minimizadas por el autor: ni las cocineras, muy importantes en tanto garantizaban la alimentación de las tropas durante las movilizaciones y los combates, ni menos aún la representación de mujeres sojuzgadas, sino las que marcaron importantes pautas transgresoras en la manera de pensar el rol femenino al frente de los combates, con una participación directa de tanta importancia como la que desarrollaron los hombres.

Desde la literatura se hacía especial énfasis en un rol que no se diferenciaba del que en la historia habían protagonizado los líderes masculinos de diferentes estados. En 1944, el mayor interés de la novela no se circunscribía a los genuinos hacedores y relatores de la historia, los hombres, en calidad de jefes militares cristeros, como Victoriano Ramírez (El Catorce), de Los Altos; Pedro Quintanar y Aurelio Acevedo, en Jalisco y Zacatecas respectivamente; Rodolfo Gallegos, en Guanajuato; Jacinto Loyola y Prudencio Zapata, en San Luis Potosí o Jesús Degollado Guízar, en Michoacán, sino en las mujeres católicas que en relación directa y cotidiana con los hombres participaron en la lucha que se libraba en el campo de batalla, bien lejos de ser consideradas como simples espectadoras de lo que sucedía.

Es importante tener en cuenta que la novela se escribió y luego se publicó en una época signada bajo el estereotipo de la mujer mexicana

\footnotetext{
${ }^{30}$ Goytortúa Santos, Pensativa, p. 65.
} 
católica indisolublemente ligada a lo doméstico y cotidiano, porque en el hogar fue la encargada de salvaguardar el comportamiento y velar por la educación formal de sus hijos. En este sentido Goytortúa sugiere al lector una mirada diferente en torno a la preservación de las tradiciones de los años veinte del pasado siglo.

Mujeres consideradas socialmente de y para los hombres, debían contribuir a la patria y la cristiandad, pero sobre todo y ante todo a la familia. Dentro de la estructura familiar mexicana las madres, mujeres, esposas y hermanas protegían las buenas costumbres proporcionando el entorno requerido, ${ }^{31}$ pero fueron también las que a partir de 1926 ejercieron la presión psicológica en los hombres a fin de incitarlos a la realización de determinadas acciones, en este caso a afiliarse a la lucha armada.

La actuación de Pensativa reflejaba la imagen "combatiente" de la mujer rural que abandonaba su hogar para incorporarse a la refriega. La guerra a su paso había incidido en la formación y la vida de los mexicanos del centro-occidente, por ello Pensativa refiere en uno de los pasajes que ha pensado vivir en un convento, porque "jamás he podido pensar en casarme. La guerra religiosa estalló cuando me hacía mujer y ya no tuve un instante de tranquilidad, todo fue zozobras. Estuve siempre rodeada de peligros". La mujer que desafió el peligro a partir de 1926 lo hacía convertida en generala de las huestes cristeras. Su relevancia radicaba en el hecho de constituir "la única que supo reunir a los indisciplinados caudillos con valor, entereza y mucho coraje en la lucha contra los federales". 32

Aunque el autor nos relata el papel de Carlos Infante como jefe cristero, reafirma la valentía femenina a partir de las vivencias que experi-

\footnotetext{
${ }^{31}$ González Montes y Muñón, comps., Familias y mujeres en México, México, El Colegio de México, 1997, 118.

${ }^{32}$ Luis Gachuz Meza al estudiar el trabajo de las mujeres en Los Altos de Jalisco durante el conflicto de los cristeros considera que la rebelión (1926-1929) es quizás uno de los más oscuros e inexplorados periodos de la historia mexicana y más aún el rol de las mujeres dentro del mismo. Su reflexión a partir del estudio de los diarios de Conchita Alcala y Josefina Arellano de Huerta nos acercan al conocimiento, tanto dentro de la organización femenina Brigada Santa Juana de Arco como al desempeño de las mujeres que facilitaron el envío de información arriesgando sus vidas. Véase Gachuz Meza, Women, freedom, and god: The Cristero Rebellion and the Work of women in Small Towns of Los Altos, disponible en www-mcnair.berkeley.edu/ 2002journal.
} 
mentó cada uno de ellos. Su intención no fue presentar a Pensativa ni como mujer culta resuelta a ser la transformadora social por excelencia, ni la víctima de la explotación, vejaciones o discriminación propias de su época, sino conferirle una relevancia como jefe militar. Su papel fue retomado desde los mismos hechos de la historia, porque como refiere Jean Meyer, en algunos estados de México, las mujeres:

[...] eran las primeras en declarar la guerra, y los peores enemigos de los federales, que lo pagaban con creces [...] El alma de la resistencia en Huejuquilla fue María del Carmen Robles, que supo resistir al general Vargas, y cuyo martirio le valió una fama de santidad. María Natividad C. González llamada "la generala Tiva" era la tesorera de la Brigada Quintanar, mientras que [...] Agripina Montes "La coronela" [...] organizó el alzamiento de Manuel Frías, en Colón, y lo propagó por toda la región con una energía absolutamente militar $[\ldots]^{33}$

La caracterización de Pensativa como la joven que "ha sufrido y sufre aún por los hechos sangrientos y crueles que vivió durante la persecución religiosa que llevó a cabo el gobierno mexicano", nos devela el interés del novelista en presentarnos el componente humano de su protagonista. Ha vivido desde pequeña en su hacienda del Plan de los Tordos, cerca del camino viejo a Guanajuato, pero en 1929, sin familia, y en una "casa desmantelada", vive rodeada de mujeres y hombres cristeros que también han sufrido los horrores de la rebelión y presentan en sus rostros y cuerpos las cicatrices recibidas de las fuerzas del gobierno. Los ha acogido en su hogar cuando el conflicto ha finalizado por el hecho de haber sido "valientes que lo dejaron todo por defender la fe", ${ }^{34}$ pero además porque todos estuvieron en la lucha armada bajo las órdenes de su hermano Carlos.

Sin embargo, el novelista también nos conduce a su identidad y significación como "mujer terrible y despiadada" en medio del fanatismo cristero. Refiere el novelista el interés del protagonista Roberto por conocer el misterio que cubre a esta mujer, lo cual se devela a partir de una

\footnotetext{
${ }^{33}$ Meyer, ob. cit., t. III, pp. 24-25.

${ }^{34}$ Goytortúa Santos, Pensativa, p. 39
} 
carta enviada desde Guadalajara donde las características que asumió Pensativa en la guerra salen finalmente a la luz:

[...] Entrevisté a viejos cristeros que la conocieron y que hablan de ella con veneración y todos han negado la muerte de la generala. La terrible mujer está oculta y estos fanáticos no pueden ni siquiera imaginársela muerta. La adoran. Fue una mujer temeraria, dura, impávida, que apareció repentinamente en los campos de la lucha y que pronto se hizo conocer como la generala, sin otro nombre. Apenas los íntimos conocieron el nombre de esa misteriosa mujer que fue el alma de la guerra. La han comparado con Juana de Arco, pero la Doncella de Orleans no fue jamás ni tan intrépida ni tan despiadada como la Generala de los cristeros. ${ }^{35}$

Aunque Basilio, excristero, considera a la joven Pensativa "la más santa y virginal de las mujeres [...] después de Dios y de la Santísima Virgen viene la señorita", ${ }^{36}$ fue para su tropa la líder en la guerra. Para todos los amigos que le hacen canciones para mitigar su tristeza, pero que conocen su misterio, no fue el sacerdote o militar inexperto que los guió de manera desorganizada, sino la que supo dirigir un ejército, representando además "a una linda mujer" que jamás pudo ser vencida ni doblegada por la fuerza del gobierno en los estados de Jalisco y Colima porque "sabía mandar mejor que los hombres". ${ }^{37}$

La mujer-líder, "la terrible cabecilla de los cristeros" ${ }^{\prime 38}$ en tanto mandaba a hombres, debía camuflarse en la época bajo una identidad masculina, elemento que destaca Goytortúa. En el México de fines de los años veinte no bastaba la valentía y destreza de una joven como Pensativa, "hermosa, melancólica y de fina raza", sino que debía "enmascarar" su físico y peleaba disfrazada de hombre, sustituyendo las faldas por los pantalones para ser aceptada por sus propios subalternos en su condición de dirigente. Según Goytortúa era una temible y decidida mujer, una heroína católica que bajo el disfraz de un hombre en los

\footnotetext{
${ }^{35}$ Goytortúa Santos, Pensativa, p. 234.

${ }^{36}$ Goytortúa Santos, Pensativa, p. 98.

${ }^{37}$ Goytortúa Santos, Pensativa, p. 71.

${ }^{38}$ Goytortúa Santos, Pensativa, p. 77.
} 
combates le había asegurado al enemigo federal considerables bajas en su ejército.

El novelista nos presentó a la mujer que por una parte no se refugió en cañadas, desfiladeros, peñas o cuevas para evadir el peligro de los cristeros u ocultarse de las fuerzas callistas como lo hicieron otras, porque en este caso Pensativa fue "la generala" que defendió con las armas, por espacio de tres años, el derecho a profesar su religión. Por otra parte, fue importante la representación de las que en franco desafío contra un ejército superior y bien armado se desarrollaron en medio de la inseguridad y las vejaciones de una guerra. Ciertamente, tal y como refiere Ana Lau Gaiven,

las mujeres mexicanas jugaron un papel muy importante en esta rebelión por creer que eran ellas las depositarias de los valores de la fe cristiana. [Su papel fundamental lo desempeñaron] ayudando económicamente a la causa, [participando físicamente en los hechos armados, aunque también] asistiendo clandestinamente a los cultos cuando fueron prohibidos o militando contra el gobierno. ${ }^{39}$

Mujeres identificadas con el sacrificio y el coraje y entregadas a la fidelidad de una causa se rescataron en la novela. Agustín Vaca ha considerado que el elemento femenino desempeñó un papel decisivo en la rebelión y que en los hechos del conflicto aventajaban indiscutiblemente a los hombres, aseverando que "la mayoría de novelas de tema cristero, coinciden en señalarlas como las principales promotoras e instigadoras de la rebelión". ${ }^{40}$

El servicio de la hacienda, cubierto fundamentalmente por las mujeres, aparece sin detalles significativos. No obstante, el interés se ha centrado en los personajes femeninos que muestran algunas señales de la guerra en la que han intervenido, tal es el caso de "Mariana, la más vieja, que había sufrido la amputación de la mano izquierda; Lucía, la más joven, que amamantaba a su hijo, pero mostraba en la frente un trazo que

\footnotetext{
${ }^{39}$ Lau Gaiven, La nueva ola del feminismo en México, México, Grupo Editorial Planeta,

${ }^{40}$ Vaca, Los silencios de la historia: Las cristeras, México, El Colegio de Jalisco, 1998, 21.
} $1987,38$. 
[...] había sido dejado por una bala". ${ }^{41}$ La cruenta realidad que se vivió en el periodo 1926-1929 trastocó el rol femenino dependiente hasta el punto de considerar a las mujeres en la rebelión como el sustento clandestino de mayor efectividad e independencia.

Las acompañan fielmente en la hacienda los hombres católicos, "hombres admirables", al decir de Pensativa, que aún se enorgullecen cuando los nombran cristeros. Ellos, en 1929, tras la culminación de la rebelión, no han sido colgados, fusilados o desorejados, aunque son seres mutilados e impedidos que no pueden trabajar fácilmente por ser cojos, mancos o tuertos y los que según sus propias palabras no pueden tropezar nunca con sus enemigos implacables que son los hombres que representan al Jefe Máximo de la revolución mexicana, el general Plutarco Elías Calles.

El centro de la atención del novelista Jesús Goytortúa Santos fue una líder de los cristeros cuya tipología y escenario "de lucha" no fue el hogar, sin embargo, hizo gala de especial cuidado al caracterizar ambos bandos sin dejar de describir las acciones y venganzas protagonizadas por las fuerzas federales y cristeras, por ello se constata en su novela su neutralidad ante el tema histórico que tomó como motivación. En sus páginas se reiteró con insistencia la existencia de una guerra donde desde ambos bandos se cometieron acciones despiadadas. Lo anterior se enfatizó también a partir del relato de dos actitudes femeninas completamente opuestas. Se conoce la anécdota de doña Ursula, quien sufrió un castigo de parte de las tropas del gobierno federal y fue echada al río por los soldados por haber ayudado a los grupos cristeros, pero por otro lado los cristeros, si bien habían recibido dinero para la causa rebelde de doña Enedina, calificaron su ayuda de actitud tibia por haber escondido en 1928, en el ropero de su casa al gran maestro de la masonería, el secretario del Ayuntamiento del pueblo.

A Goytortúa le interesó el rescate de las mujeres que auxiliaron a los hombres en el combate, los "cristeros pacíficos" al decir de la investigadora mexicana Marta Elena Negrete, sin los cuales el movimiento cristero no hubiera subsistido por mucho tiempo porque proporcionaban

\footnotetext{
${ }^{41}$ Goytortúa Santos, Pensativa, p. 65.
} 
alimentos y protección. ${ }^{42}$ Le interesó al novelista relatar la ayuda que brindaron las que, sin ser propiamente líderes en los combates, ayudaron en la rebelión con dinero, noticias, ropas y parques, tuvieron a su cargo el transporte de la correspondencia, el traslado de parque para los combatientes y la misión de curar a los heridos en el combate como enfermeras o auxiliadoras. Mujeres que sin tener en cuenta las exigencias, discriminación y preocupaciones sociales respecto a ellas, colaboraron de varias maneras, tal fue el caso de Genoveva, la Chacha, otro de los personajes femeninos, quien afirmaba con orgullo:

Yo fui cristera. No anduve con las armas en la mano, pero hice lo que tu tía y lo que por aquí todo el mundo hizo: ayudar a los rebeldes [...] podíamos con relativa facilidad pasar avisos, dinero y medicinas y hasta parque a los diferentes grupos cristeros que operaban en la zona [...] Teníamos que usar muchas precauciones y éramos más desconfiadas que los coyotes. ${ }^{43}$

La novela Pensativa rescataba un sujeto histórico con el objetivo de inmortalizar su proceder, pero también asentaba el deseo consciente de dejar para la posteridad lo específicamente femenino con su peculiar mezcla de dulzura, debilidad, carácter y sensibilidad junto a los hombres que se enrolaron en la primera rebelión cristera, para afrontar "su" causa, alejada del marco limitado del hogar familiar y las labores del culto, más a tono con la imagen tradicional de la mexicana.

Las mujeres que nos mostró Goytortúa ni rezaron constantemente, ni se sintieron amparadas por una profesión, "muchachas casi todas condenadas a morir solteras por la emigración de los hombres" que fueron a la guerra. No fueron idílicas, sino seres de pueblo, mayoritariamente campesinas cuya única motivación había sido dirigir, en otras ocasiones sólo colaborar de varias maneras con la campaña que habían protagonizado los sublevados. Sus voces se habían alzado enardecidas en un clamor popular con la convicción de que habían actuado correctamente, porque no existía otro camino posible para ellas que la continuación de sus hábitos y tradiciones, interrumpidas a partir de 1926.

\footnotetext{
${ }^{42}$ Negrete, Enrique Gorostieta. Cristero agnóstico, México, Ediciones El Caballito, 1981, 36.

${ }^{43}$ Goytortúa Santos, Pensativa, p. 112.
} 
La mujer, discriminada socialmente, se visualizó dentro de Pensativa como ente activo de las acciones político-religiosas que se libraban. Su rol no se circunscribió a las labores que se consideraron las propias de su sexo, sino a las que la sociedad católica le impuso como parte de su universo como madre y hermana junto a sus compañeros, esposos, hijos o hermanos. Sin duda, al decir del historiador Jean Meyer, la lucha por espacio de tres años no hubiera podido mantenerse sin la ayuda constante de las mujeres de una u otra posición social que actuaron en calidad de espías, de aprovisionadoras, de organizadoras, sobre las que recaía todo el peso de la logística y de la propaganda. ${ }^{44}$

Llegar a aprehender este quehacer en toda su diversidad y complejidad no es tarea fácil, una vez que las grandes narrativas nacionales, como los bosques, apenas permiten divisar los múltiples elementos que integran "la nación". He aquí la importancia de la novela como fuente histórica: crear y recrear la participación de otros segmentos sociales como las mujeres, hacedores también de historia y cultura.

\section{CONSIDERACIONES FINALES}

Un acontecimiento polémico y complejo como el conflicto de los cristeros (1926-1929) dejó profundas huellas en toda la nación. Sus hechos y sus protagonistas representan un difícil entramado de posiciones, conductas y actitudes, y la novela lo recogió con extrema minuciosidad. Las mujeres mexicanas no quedaron excluidas en el intento, porque la historia a través de la literatura las ha albergado en su acervo como las depositarias de una tradición de lucha, bien alejadas de una posición retardataria o secundaria, sino como poseedoras de una vitalidad y energía de gran relevancia.

Las novelas de tema cristero comenzaron a ser leídas y a circular en México de manera clandestina cuando la historia oficial mantuvo un absoluto silencio sobre las incidencias de la rebelión. La novela Pensati$v a$, en 1944, se anticipaba a las fuentes históricas en cuanto a la representación de la mujer cristera y su desempeño. Fue, un símbolo que enlazó la ficción con la historia, rescatando desde la literatura la expresión y el

${ }^{44}$ Meyer, Jean, La Cristiada, t. I, 1997, 75. 
liderazgo de una mujer que constituía un ejemplo de exaltación y valentía, a su vez reconstruidos por Jesús Goytortúa Santos a partir de una lectura del pasado histórico de la nación.

A través de su novela incorporó al heterogéneo elemento femenino a la narrativa como símbolos de identidad nacional y portadoras de una fuerza singular negada por la historia. Por ello la necesidad del estudio de la literatura como fuente, y a su vez reflejo de ella, con vistas a desentrañar un imaginario que inevitablemente nos guía hacia su rol activo, amplio y enriquecedor. Sin estudiar a la mujer mexicana no es posible completar una verdadera historia sea política, ideológica, social o cultural. Sin indagar en sus matices, su capacidad y en su pasado es imposible hacer la historia del siglo xx de México.

\section{BiBLIOGRAFÍA}

AIRA, César, Diccionario de autores latinoamericanos, Buenos Aires, Emecé Editores, 2001.

Alegría, Fernando, Breve historia de la novela hispanoamericana, México, Ediciones de Andrea, 1945.

Arias Urrutia, Ángel, Cruzados de novela: Las novelas de la guerra cristera [en línea], Ediciones Universidad de Navarra (Disponible en www. etcetera.com.mx) (Consultada en noviembre del 2008).

Aub, Max, Guía de narradores de la revolución mexicana, México, Fondo de Cultura Económica, 1969.

Brushwood, John S., México en su novela, México, Fondo de Cultura Económica, 1993.

CASTELLANOS, Luis Arturo, La novela de la revolución mexicana, Rosario, Facultad de Filosofía, 1968.

Fuentes MARes, José, Biografía de una nación (De Cortés a López Portillo), México, Ediciones Océano, 1982.

GaChuz MeZA, Luis, Women, freedom, and god: The Cristero Rebellion and the Work of women in Small Towns of Los Altos [en línea] (Disponible en www-mcnair.berkeley.edu/2002journal) (Consultada en octubre 2008).

GonzÁlez, Manuel Pedro, Trayectoria de la novela en México, México, Ediciones Botas, 1951. 
GonzÁlez Montes, Soledad y Julia Tuñón, comps., Familias y mujeres en México, México, El Colegio de México, 1997.

Gơtortúa SAnTos, Jesús, Pensativa, México, Editorial Porrúa, 1945.

HernáNDEz López, Conrado, Historia y novela histórica, México, El Colegio de Michoacán, 2004.

Lau Gaiven, Ana, La nueva ola del feminismo en México, México, Grupo Editorial Planeta, 1987.

Marinello Vidaurrutia, Juan, “Treinta años después. Notas sobre la novela latinoamericana", en Recopilación de textos sobre tres novelas ejemplares, La Habana, Serie Valoración Múltiple Casa de las Américas, 1975.

Martínez Assad, Carlos, "Regiones en la historia y en la literatura", en Conrado Hernández López, Historia y novela histórica, México, El Colegio de Michoacán, 2004.

Martínez, José Luis, Literatura mexicana S. xx (1910-1949), México, Antigua Librería Robredo, 1949.

Mendieta AlatorRe, Ángeles, La mujer en la revolución mexicana, México, Talleres Gráficos de la Nación, 1961.

MeYER, Jean, La cristiada, México, Siglo XXI editores, tomos I, II y III,1973.

Negrete, Marta Elena, Enrique Gorostieta. Cristero agnóstico, México, Ediciones El caballito, 1981.

OCAMPO DE GÓMEz, Aurora Maura, Literatura mexicana contemporánea. Biobibliografía crítica, México, UNAM, 1965.

Olivera De BonflL, Alicia, La literatura cristera, México, Instituto Nacional de Antropología e Historia, 1970.

PORTAL, Marta, Proceso narrativo de la revolución mexicana, Madrid, Espasa-Calpe, 1980.

Ruzz AвREu, Álvaro, La cristera una literatura negada (1928-1992), México, Universidad Autónoma Metropolitana-Xochimilco, 2003.

SCHNEIDER, Luis Mario, La literatura mexicana, Buenos Aires, Centro Editor de América Latina, t. II, 1967,

VACA, Agustín, Los silencios de la historia: Las cristeras, México, El Colegio de Jalisco, 1998.

FECHA DE RECEPCIÓN DEL ARTícULO: 28 de marzo de 2009

FECHA DE ACEPTACIÓN Y RECEPCIÓN DE LA VERSIÓN FINAL: 20 de abril de 2010 